\title{
Localization, mechanism and reduction of renal retention of technetium-99m labeled epidermal growth factor receptor-specific nanobody in mice
}

\author{
Lea Olive Tchouate Gainkam ${ }^{a *}$, Vicky Caveliers ${ }^{a, b}$, Nick Devoogdta \\ Christian Vanhove ${ }^{a, b}$, Catarina Xavier ${ }^{a}$, Otto Boerman ${ }^{d}$, \\ Serge Muyldermans ${ }^{c}$, Axel Bossuyt ${ }^{b}$ and Tony Lahoutte ${ }^{a, b}$
}

\begin{abstract}
Background: Nanobodies are single-domain antigen binding fragments derived from functional heavy-chain antibodies elicited in Camelidae. They are powerful probes for radioimmunoimaging, but their renal uptake is relatively high. In this study we have evaluated the role of megalin on the renal uptake of anti-EGFR ${ }^{99 m}$ Tc-7C12 nanobody and the potency of gelofusine and/or lysine to reduce renal uptake of ${ }^{99 \mathrm{~m}} \mathrm{Tc}-7 \mathrm{C} 12$.

Methods: First we compared the renal uptake of ${ }^{99 \mathrm{~m}} \mathrm{Tc}-7 \mathrm{C} 12$ in megalin-deficient and megalin-wild-type mice using pinhole SPECT/microCT and ex vivo analysis. The effect of gelofusine and lysine administration on renal accumulation of ${ }^{99 \mathrm{~m}}$ Tc-7C12 was analyzed in CD-1 mice divided into lysine preload at $\mathbf{3 0}$ min before tracer injection (LysPreload), LysPreload + gelofusine coadministration (LysPreload + GeloCoad), lysine coadministration (LysCoad), gelofusine coadministration (GeloCoad) and LysCoad + GeloCoad. The combined effect of gelofusine and lysine on tumor uptake was tested in mice xenografts.

Results: Renal uptake of ${ }^{99 m} \mathrm{mc}-7 \mathrm{C} 12$ was $44.22 \pm 3.46 \%$ lower in megalin-deficient compared with megalinwild-type mice. In CD-1 mice, lysine preload had no effect on the renal retention whereas coinjection of lysine or gelofusine with the tracer resulted in $25.12 \pm 2.99$ and $36.22 \pm 3.07 \%$ reduction, respectively. The combined effect of gelofusine and lysine was the most effective, namely a reduction of renal retention of $45.24 \pm 2.09 \%$. Gelofusine and lysine coadministration improved tumor uptake.

Conclusion: Megalin contributes to the renal accumulation of ${ }^{99 m} \mathrm{Tc}-7 \mathrm{C} 12$. Gelofusine and lysine coinjection with the tracer reduces the renal uptake while tumor uptake is improved. Although this methodology allows for optimization of imaging protocol using nanobodies, further improvements are needed before using these molecules for radionuclide therapy. Copyright (C) 2010 John Wiley \& Sons, Ltd.
\end{abstract}

Keywords: nanobody; lysine; gelofusine; kidneys; megalin

\section{INTRODUCTION}

Small antibody fragments are promising for tumor targeting because their small size allows them to penetrate deep into tumor tissues. For imaging applications they have the advantage that they are more rapidly cleared from the circulation compared with intact monoclonal antibodies, providing high tumor-tobackground ratios at relatively early time points (1). Moreover, coupling with therapeutic radionuclides allows targeted radionuclide therapy. Many different formats have been investigated including nanobodies, minibodies, diabodies (1-4), scFvs, Fabs and $F(a b) 2(5,6)$. Each format has its own pharmacokinetic profile with a blood clearance that is largely dependent on the molecular size. A size below the renal threshold for glomerular filtration $(60 \mathrm{kDa})$ typically results in a high first-pass renal clearance. We are investigating radiolabeled nanobodies (derived from the heavy chain antibodies of (amelidae) as a new group of antibody-based agents for clinical molecular imaging and radionuclide therapy. Nanobodies are small $(15 \mathrm{kDa})$ intact antigen binding fragments derived from single-domain heavy-chain
* Correspondence to: L. O. Tchouate Gainkam, ICMI, In vivo Cellular and Molecular Imaging Laboratory, Vrije Universiteit Brussel, Laarbeeklaan 103, 1090 Brussels, Belgium.

E-mail: Itchouat@vub.ac.be

a L. O. Tchouate Gainkam, V. Caveliers, C. Vanhove, C. Xavier, T. Lahoutte, N. Devoogdt

ICMI, In vivo Cellular and Molecular Imaging Laboratory, Vrije Universiteit Brussel, Brussels, Belgium

b V. Caveliers, C. Vanhove, A. Bossuyt, T. Lahoutte Nuclear Medicine Department, UZ Brussel, Brussels, Belgium

C S. Muyldermans

Department of Molecular and Cellular Interactions, VIB, Brussels, Belgium Laboratory of Cellular and Molecular Immunology, Vrije Universiteit Brussel, Brussels, Belgium

d O. Boerman

Department of Nuclear Medicine, Radboud University Hospital, Nijmegen, The Netherlands 
antibodies. They are the smallest antibody-based fragments that can be engineered at present and their small size enables them to recognize unique hidden epitopes that are less accessible for conventional antibodies (7). With the recent identification of a universal humanized nanobody scaffold, these probes are now also ready for clinical translation $(8,9)$. In our previous work we identified ${ }^{99 m}$ Tc-7C12 nanobody (Ablynx NV) as the lead compound for monitoring EGFR expression of cancer based on its high tumor uptake, fast blood clearance and low liver uptake $(10,11)$. High-contrast images of EGFR-expressing lesions can be obtained as early as $1 \mathrm{~h}$ post injection (p.i.). However, the organs with the highest accumulation are the kidneys. This might limit the sensitivity of detecting a specific molecular signal in the vicinity of the kidneys. High renal accumulation is also a limiting factor for applications of radionuclide therapy using nanobodies. This problem is common to other small peptides and antibody fragment-based probes. It is believed to be related to the extensive apical endocytic apparatus of the renal proximal tubule that is responsible for reabsorption of molecules filtered in the glomeruli. Several key receptors appear to be involved in this function with megalin receptor as probably the most important receptor in the endocytosis process (12). Megalin is a $600 \mathrm{kDa}$ multiligand endocytic recepor belonging to the lowdensity lipoprotein receptor. It is heavily expressed in the renal proximal tubule and involved in protein reabsorption.

Several possible strategies to reduce renal reabsorption of receptor-specific radiopharmaceuticals (peptides and antibody fragments) have been successfully employed. These include infusion of cationic amino acids (e.g. lysine, arginine or the combination), modifications of physicochemical characteristics of the agent such as introduction of a saccharide moiety, or increasing the number of negative charges in the proteins or peptides (13-15). Recently several groups also reported a renal reduction of radiolabeled peptides using gelatin-based plasma expanders like gelofusine (16-18).

The aim of this report was to investigate the role of the megalin receptor in the accumulation of ${ }^{99 \mathrm{~m}} \mathrm{Tc}-7 \mathrm{C} 12$ nanobody in the kidneys and to test the possibility of reducing kidney retention by L-lysine and/or gelofusine administration.

\section{MATERIALS AND METHODS}

\subsection{Nanobody labeling}

7C12 nanobody was a kind gift from Ablynx, Ghent, Belgium. It was generated and purified as described previously (19). 7C12 was labeled as described by Gainkam et al. (10). Briefly, $50 \mu \mathrm{g}$ of $7 \mathrm{C} 12$ was added to $\left[{ }^{99 \mathrm{~m}} \mathrm{Tc}\left(\mathrm{H}_{2} \mathrm{O}\right)_{3}(\mathrm{CO})_{3}\right]^{+}$prepared using a Isolink kit (Mallinckrodt Medical, Petten, The Netherlands) and the mixture was incubated for $90 \mathrm{~min}$ at $50^{\circ} \mathrm{C}$ in a water bath. The unreacted $\left[{ }^{99 m} \mathrm{Tc}\left(\mathrm{H}_{2} \mathrm{O}\right)_{3}(\mathrm{CO})_{3}\right]^{+}$was separated from the labeled compound using a NAP-5 column (GE Healthcare, Diegem, Belgium) preequilibrated with $10 \mathrm{ml}$ phosphate buffered saline (PBS) and passed through a $0.22 \mu \mathrm{m}$ Millipore filter (Millipore S.A./ N.V., Brussels, Belgium). The labeling efficiency was determined by instant thin-layer chromatography (ITLC) in acetone and was always more than $90 \%$. The radiochemical purity of the used tracer was always greater than $99 \%$.

\subsection{Cell culture and animal models}

The human skin carcinoma cell line A431 was obtained from EPO-GmbH (Berlin-Buch, Germany). It expresses about $2 \times 10^{6}$
EGFR molecules per cell (20). The cells were cultured in Dulbecco's modified Eagle's medium (DMEM),(Invitrogen, Paisley, UK) supplemented with $10 \%$ fetal bovine serum, L-glutamine $\left(2 \mathrm{mmol} \mathrm{I}^{-1}\right)$ and PEST (penicillin $100 \mathrm{IU} \mathrm{ml}^{-1}$ and streptomycin $100 \mu \mathrm{g} \mathrm{ml}^{-1}$ ), $1 \%$ $\mathrm{Na}+$ pyruvate and $1 \%$ non-essential amino acids all obtained from Invitrogen (Paisley, UK). The cells were collected with trypsin-ethylenediamine tetraacetic acid (EDTA) 0.05\% (Invitrogen). Cells were grown at $37^{\circ} \mathrm{C}$ in a humidified air incubator equilibrated with $5 \% \mathrm{CO}_{2}$. Female megalin-deficient and megalinexpressing mice were developed in the laboratory of Professor Thomas Willnow $(21,22)$; they were bred and PCR screened in the laboratory of Professor Otto Boerman. Healthy male (ICR/CD1) mice were purchased from Harlan (Horst, The Netherlands). Tumor xenografts were obtained by inoculating A431 cells $\left(3 \times 10^{6}\right)$ in $150 \mu$ l PBS ( $\left.\mathrm{pH} 7.4\right)$ subcutaneously into the right hind of 6-week-old athymic nude mice (Harlan) under the control of $2.5 \%$ isoflurane (Abbott, Ottignies LLN, Belgium). Tumors were allowed to grow for 10-14 days, when the diameter of the tumor reached $0.5-1 \mathrm{~cm}$. The study protocol was approved by the ethical committee for animal research of our institution.

\subsection{High-performance liquid chromatography}

HPLC was performed using a Merck Hitachi L-7100 (VWR, Haarsrode, Belgium) coupled to a UV-vis detector L-7400 (VWR, Haarsrode, Belgium, detection wavelength $280 \mathrm{~nm}$ ) and a $\gamma$-detector (LB 507 B, Berthold, Bad Wildbad, Germany). Analytical separations were achieved by size exclusion chromatography (SEC) on a Superdex 75 10/300 GL column (GE Healthcare, Upsala, Sweden) preequilibrated with $0.01 \mathrm{~m}$ phosphate buffer ( $\mathrm{pH} \mathrm{7.4)} \mathrm{at}$ a flow rate of $0.5 \mathrm{ml} \mathrm{min}-1$.

\subsection{In vitro stability}

${ }^{99 m} \mathrm{Tc}-7 \mathrm{C} 12(100 \mu \mathrm{l}, 37 \mathrm{MBq})$ was added to $900 \mu \mathrm{l}$ of human plasma or $300 \mu \mathrm{l}$ PBS and incubated at $37^{\circ} \mathrm{C}$ and room temperature respectively. SEC-HPLC was performed at 6 and $24 \mathrm{~h}$ for serum sample and at 1 and $24 \mathrm{~h}$ for PBS.

\subsection{In vivo stability}

Nude athymic mice were intravenously injected with 39.42-67.33 $\mathrm{MBq}$ of ${ }^{99 \mathrm{~m}} \mathrm{Tc}-7 \mathrm{C} 12$ and euthanized at $1 \mathrm{~h}$ p.i. with a lethal dose of pentobarbital (Nembutal, CEVA, Brussels, Belgium). The kidneys, urine and a blood sample were collected. The kidneys were mashed in $0.25 \mathrm{ml}$ EBC buffer $(170 \mathrm{~mm} \mathrm{NaCl}, 10 \mathrm{~mm}$ EDTA, $50 \mathrm{~mm}$ Tris pH 7.4, $50 \mathrm{~mm} \mathrm{NaF,} \mathrm{0.5 \%} \mathrm{NP-40)} \mathrm{supplemented} \mathrm{with} \mathrm{protease}$ inhibitor (Roche, Mannheim, Germany), incubated on ice for $20 \mathrm{~min}$ and centrifuged at $4^{\circ} \mathrm{C}$ for $15 \mathrm{~min}$ at $14000 \mathrm{rpm}$. Urine was filtered through a Millex GV filter $(0.22 \mu \mathrm{m})$ before analysis. The ${ }^{99 \mathrm{~m}} \mathrm{Tc}-7 \mathrm{C} 12$ in urine or the supernatant of the kidneys homogenate was analyzed by SEC-HPLC. The serum could not be analyzed because no radioactivity could be detected.

\subsection{Autoradiography}

Kidneys were collected from mice injected with ${ }^{99 \mathrm{~m}} \mathrm{Tc}-7 \mathrm{C} 12$ at $1 \mathrm{~h}$ p.i., embedded in tissue-Tek ${ }^{\circledR}$ OCT $^{\mathrm{TM}}$ compound (Sakura Finetek, Zoeterwoude, The Netherlands) and frozen immediately in liquid nitrogen. Cryosections of $10 \mu \mathrm{m}$ were made at $-20^{\circ} \mathrm{C}$. Autoradiographic images $(10 \mathrm{~min})$ of renal slices were acquired 
using the Microimager (Biospace, France). Images were visualized with $\beta$-vision + software (Biospace, France).

\subsection{Renal uptake of ${ }^{99 \mathrm{~m}} \mathrm{Tc}-7 \mathrm{C} 12$ in megalin-deficient mice}

Female $\mathrm{C} 57 \mathrm{BI} / 6$ megalin-deficient and megalin-wild-type mice were intravenously injected with $39.96-66.60 \mathrm{MBq}$ of ${ }^{99 \mathrm{~m}} \mathrm{Tc}-7 \mathrm{C} 12$ in $100 \mu \mathrm{l}$ PBS (containing $4.5 \mu \mathrm{g} 7 \mathrm{C} 12$ ). At $1 \mathrm{~h}$ p.i. mice were anesthetized with a mixture of $18.75 \mathrm{mg} \mathrm{kg}^{-1}$ ketamine hydrochloride (Ketamine $1000^{\circledR}$, CEVA, Brussels, Belgium) and $0.5 \mathrm{mg} \mathrm{kg}^{-1}$ medetomidin hydrochloride (Domitor ${ }^{\mathbb{R}}$, Pfizer, Brussels, Belgium). Total body pinhole SPECT/microCT was performed as described previously (10). Briefly, microCT imaging (Skyscan 1178, Aartselaar, Belgium) was followed by pinhole SPECT (e.cam180 Siemens Medical Solutions, IL, USA) on separate imaging systems and images were fused automatically using six ${ }^{57}$ Co sources based on a mathematical software (23). MicroCT images were reconstructed using filtered backprojection (Nrecon, Skyscan). Total body pinhole SPECT was performed using a dual-headed gamma camera, mounted with two triplepinhole collimators (pinhole opening, $1.5 \mathrm{~mm}$ ) and images were reconstructed using an iterative reconstruction algorithm modified for the three-pinhole geometry. Images were viewed and analyzed using AMIDE Medical Image Data Examiner software (24). Regions of interest (ROI) were drawn around the total body and the kidneys. The radioactivity in the ROls was divided by the injected activity corrected for decay, and further divided by the kidney weight (obtained after dissection) and expressed as percentage of injected activity per gram $\left(\% \mathrm{Ig} \mathrm{g}^{-1}\right)$. The total body retention (corrected for decay) at the time of imaging was calculated as ( $\{$ [counts in the total body - (counts in the tail + counts in the bladder)]/injected activity $\times \times 100$ ) and expressed as \%IA. The tracer elimination was derived from the total body retention. Immediately after pinhole SPECT, mice were euthanized at $1.5 \mathrm{~h}$ p.i. with a lethal dose of pentobarbital. The radioactivity in the blood, kidneys, liver, spleen and muscle was measured in an automated gamma counter (Cobra II Inspector 5003, Canberra-Packard, Illinois, USA) and expressed as \%IA per gram.

\subsection{Effect of gelofusine and lysine on the renal uptake of ${ }^{99 m}$ Tc-7C12 in healthy mice}

Gelofusine $40 \mathrm{~g} \mathrm{I}^{-1}$ was a kind gift from B-Braun Medical NV/SA (Diegem, Belgium). An $800 \mathrm{mg} \mathrm{ml}^{-1}$ lysine solution (Sigma Aldrich $\mathrm{GmbH}$, Steinheim, Germany) was prepared in $0.9 \% \mathrm{NaCl}$ and adjusted to $\mathrm{pH} 7.4$ with $\mathrm{HCl} 6 \mathrm{~m}$. Male ICR/CD1 mice (29-36 g) were used to evaluate the effect of $40 \mathrm{mg}(0.3 \mathrm{mmol})$ lysine and/ or $4 \mathrm{mg}(0.1 \mu \mathrm{mol})$ gelofusine on kidney uptake of ${ }^{99 \mathrm{~m}} \mathrm{Tc}-7 \mathrm{C} 12$. A total of five experimental conditions were studied: (1) lysine preload at $30 \mathrm{~min}$ before tracer injection (LysPreload); (2) lysine preload at $30 \mathrm{~min}$ before tracer injection + gelofusine coadministered with the tracer (LysPreload + GeloCoad); (3) lysine coadministration with the tracer (LysCoad); (4) gelofusine coadministration with the tracer (GeloCoad); and (5) lysine + gelofusine co-administration (LysCoad + GeloCoad) with the tracer. A group of mice injected with ${ }^{99 \mathrm{~m}} \mathrm{Tc}-7 \mathrm{C} 12$ alone served as the control group. A total of six mice were studied for each condition unless otherwise stated. Mice were euthanized at $1.5 \mathrm{~h}$ post administration of the tracer. The radioactivity in the kidneys was measured in an automated gamma counter. The kidney uptake was calculated as percentage of injected activity (\%IA) corrected for decay. The percentage of reduction of kidney uptake of ${ }^{99 \mathrm{~m}} \mathrm{Tc}-7 \mathrm{C} 12$ was calculated as follows:

$$
\begin{gathered}
\% \text { reduction }=100 \times[(\% \text { uptake in control animal } \\
-\% \text { uptake in experimental conditions }) / \\
\% \text { uptake in control animal }]
\end{gathered}
$$

\subsection{Effect of combined gelofusine and lysine administration on the biodistribution of ${ }^{99 \mathrm{~m}} \mathrm{Tc}-7 \mathrm{C} 12$ in mice bearing a tumor xenograft}

Male athymic nude mice bearing A431 tumor xenograft were used to evaluate the effect of LysCoad + GeloCoad on the biodistribution of ${ }^{99 \mathrm{~m}} \mathrm{Tc}-7 \mathrm{C} 12$ and particularly on tumor uptake. Tumor-bearing mice were intravenously injected with either 32.56-54.39 MBq of ${ }^{99 \mathrm{~m}} \mathrm{Tc}-7 \mathrm{C} 12$ in PBS (containing $2.5 \mu \mathrm{g} 7 \mathrm{C} 12$ ) alone (control) or coinjected with a mixture of $150 \mathrm{mg} \mathrm{kg}^{-1}$ of gelofusine and $1.2 \mathrm{~g} \mathrm{~kg}^{-1}$ of lysine. At $1 \mathrm{~h}$ p.i., pinhole SPECT and microCT images were obtained as described above. For image analysis, regions of interest (ROI) were drawn around the total body, kidneys, tumor and bladder on pinhole SPECT images whereas ROI of contralateral muscle and liver were drawn on CT images. The radioactivity in the ROls was divided by the injected activity corrected for decay and expressed as \%IA per cubic centimeter except for the kidneys, for which radioactivity was expressed as \%IA per gram. The tracer elimination corrected for decay at the time of imaging was calculated as described above. At $1.5 \mathrm{~h}$ p.i., the mice were euthanized with a lethal dose of pentobarbital. Blood, liver, kidneys, spleen, contralateral muscle and tumor were collected, weighed and their radioactivity content recorded in a gamma counter together with a standard of injected activity. The uptake in the tumor and other organs was expressed as \%IA per gram corrected for decay.

Blood samples were collected using a microcapillary at 1, 5, 10, 20, 40 and 60 min p.i. of ${ }^{99 \mathrm{~m}} \mathrm{Tc}-7 \mathrm{C} 12$ in both LysCoad + GeloCoad and control group in order to determine the effect LysCoad+ GeloCoad on blood clearance. The total blood volume (TBV) was calculated as $7 \%$ of the total body weight. The biological half-lives of ${ }^{99 \mathrm{~m}} \mathrm{Tc}-7 \mathrm{C} 12$ in vivo were determined using the bi-exponential non-linear regression of GraphPad Prism Software.

\subsection{Statistical analysis}

Uptake of ${ }^{99 \mathrm{~m}} \mathrm{Tc}-7 \mathrm{C} 12$ in tumor, tissues and organs was expressed as the mean \pm standard error of the mean (SEM) and compared by Mann-Whitney test for both imaging and ex vivo analysis using GraphPad Prism software. The test was considered statistically significant when the $p$-value was $<0.05$.

\section{RESULTS}

\subsection{Autoradiography}

A representative autoradiogram of a kidney slice of a mouse injected with ${ }^{99 \mathrm{~m}} \mathrm{Tc}-7 \mathrm{C} 12$ and sacrificed at $1 \mathrm{~h}$ p.i. is shown in Fig. $1 .{ }^{99 \mathrm{~m}} \mathrm{Tc}-7 \mathrm{C} 12$ is mainly concentrated in the renal cortex.

\subsection{Stability}

After incubation in PBS and human plasma at $37^{\circ} \mathrm{C}$ for up to $24 \mathrm{~h}$, only one major peak of radioactivity $(>96 \%)$ was observed with the same retention time $(27 \mathrm{~min})$ as that of intact ${ }^{99 \mathrm{~m}} \mathrm{Tc}-7 \mathrm{C} 12$ 


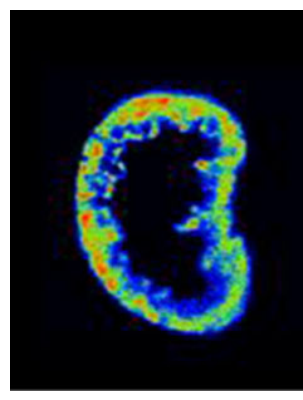

Figure 1. Ex vivo autoradiogram of renal tissue of a nude mouse injected with ${ }^{99 \mathrm{~m}} \mathrm{Tc}-7 \mathrm{C} 12$ and euthanized at $1 \mathrm{~h}$ p.i.. The radioactivity is mainly concentrated in the renal cortex.

(Fig. 2). In kidney and urine samples both intact tracer and metabolites were detected. The proportion of metabolites was 90 and $98 \%$ in the urine and kidney sample respectively.

\subsection{Renal retention of ${ }^{99 \mathrm{~m}} \mathrm{Tc}-7 \mathrm{C} 12$ in megalin-deficient mice}

The total body pinhole SPECT/microCT image of megalin-deficient mice showed less intense renal accumulation of radioactivity (Fig. 3). Image quantification at $1 \mathrm{~h}$ p.i. showed significantly lower renal retention of the tracer in megalin-deficient compared with megalin-expressing mice (105.84 \pm 6.54 vs $216.56 \pm 6.52 \% \mathrm{IA} \mathrm{g}^{-1}$; $p<0.05$ ). Furthermore, tracer elimination in megalin-knockout mice was $52.17 \pm 4.10$ vs $21.75 \pm 1.51 \% \mathrm{lA}$ in megalin-expressing mice $(p<0.05)$. The ex vivo data of ${ }^{99 \mathrm{~m}} \mathrm{Tc}-7 \mathrm{C} 12$ in megalindeficient and megalin-expressing mice are summarized in Table 1. Tracer accumulation in the blood, spleen, liver and muscle was not significantly different in both groups. Renal uptake of the tracer in megalin-deficient mice was $44.21 \pm 3.46 \%$ lower compared with megalin-expressing animals $(p<0.05)$. These data confirmed the imaging data and show that megalin plays an important role in the renal retention of ${ }^{99 m} \mathrm{Tc}-7 \mathrm{C} 12$.
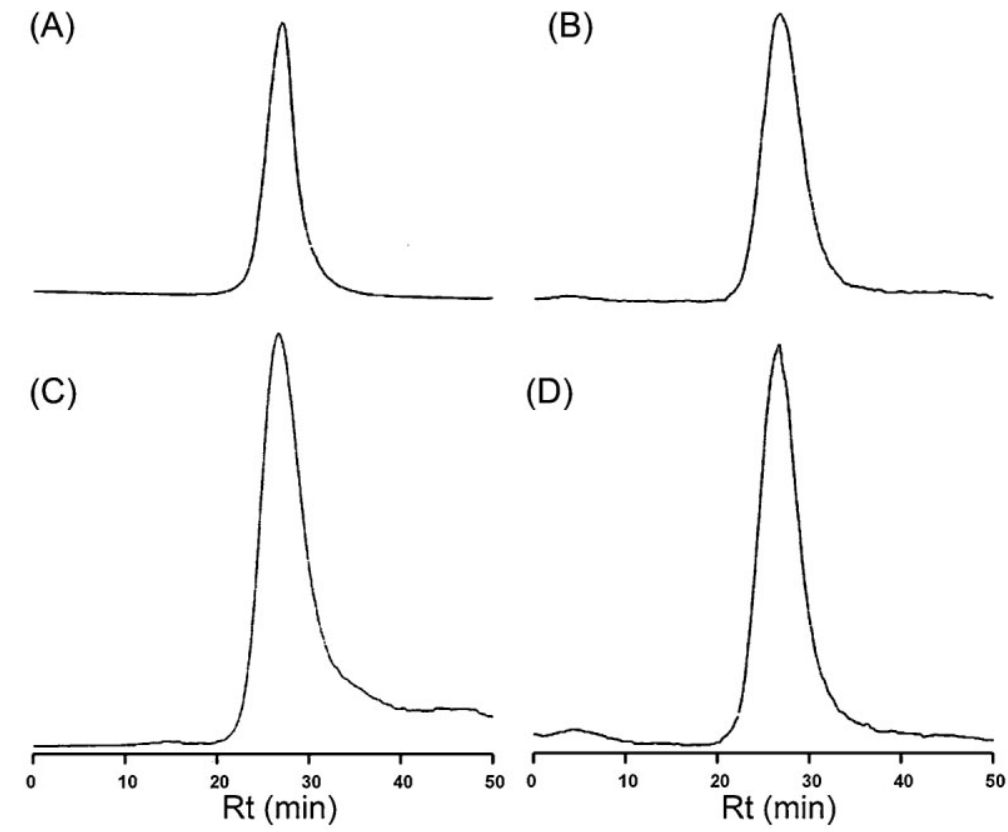

\subsection{Reduction of renal retention of ${ }^{99 \mathrm{~m}} \mathrm{Tc}-7 \mathrm{C} 12$ by gelofusine and lysine in CD-1 mice}

Lysine preload did not significantly reduce the kidney uptake of ${ }^{99 \mathrm{~m}}$ Tc-7C12 compared with the control animals (Fig. 4). However, a clear reduction of $25.1 \pm 7.3 \%$ was measured when lysine was coadministered with the tracer. Injection of gelofusine at the time of tracer injection also resulted in a strong reduction of kidney uptake: $36.2 \pm 7.5 \%$. There was no additional effect of lysine preload on the reduction caused by gelofusine administration $(p>0.05)$. The combination of lysine and gelofusine at the time of injection resulted in the strongest reduction, namely $44.2 \pm$ $5.1 \%$ ( $p<0.05$, compared with lysine coadministration), although this did not reach statistical significance compared with gelofusine coadministration.

\subsection{Effect of combined gelofusine and lysine administration on the biodistribution of ${ }^{99 \mathrm{~m}} \mathrm{Tc}-7 \mathrm{C} 12$ in mice bearing a tumor xenograft}

Mice were injected either with ${ }^{99 \mathrm{~m}} \mathrm{Tc}-7 \mathrm{C} 12$ alone (negative control) or ${ }^{99 \mathrm{~m}} \mathrm{Tc}-7 \mathrm{C} 12$ in combination with lysine and gelofusine (LysCoad+GeloCoad). Total body pinhole SPECT/microCT was acquired at $1 \mathrm{~h}$ p.i. of the compounds. As shown in Fig. 5(A), LysCoad + GeloCoad resulted in less tracer accumulation in the kidneys compared with the control $(75.75 \pm 4.99$ vs $126.41 \pm$ $\left.12.20 \% \mathrm{I}^{-1}\right)$. Tumor uptake of the tracer was significantly higher in LysCoad + GeloCoad compared with control ( $p<0.05$; Fig. 5A). The activity in the liver and muscle was similar in both groups. Tracer elimination was significantly higher in LysCoad + GeloCoad than in control group $(40.01 \pm 1.61$ vs $17.58 \pm 1.00$ respectively, $p<0.05)$. These data show that reduction of renal uptake of ${ }^{99 \mathrm{~m}} \mathrm{Tc}-7 \mathrm{C} 12$ by the combination of gelofusine and lysine does not negatively affect tumor uptake or the retention in background tissues. The ex vivo analysis of mice bearing A431 xenograft injected either with ${ }^{99 \mathrm{~m}} \mathrm{Tc}-7 \mathrm{C} 12$ alone (control) or ${ }^{99 \mathrm{~m}} \mathrm{Tc}-7 \mathrm{C} 12$ in

Figure 2. Analytical Size Exclusion Chromatography-High Pressure Liquid Chromatography (SEC-HPLC) chromatograms of ${ }^{99 \mathrm{~m}} \mathrm{TC}-7 \mathrm{C} 12 .{ }^{99 \mathrm{~m}} \mathrm{TC}-7 \mathrm{C} 12$ was incubated in PBS for $1 \mathrm{~h}$ (A) or $24 \mathrm{~h}$ (B) at room temperature. In parallel, ${ }^{99 \mathrm{~m}} \mathrm{Tc}-7 \mathrm{C} 12$ was incubated in serum for $6 \mathrm{~h}(\mathrm{C})$ and $24 \mathrm{~h}$ (D) at $37^{\circ} \mathrm{C}$. Only one major peak of radioactivity with the same retention time $(27 \mathrm{~min})$ was observed. 


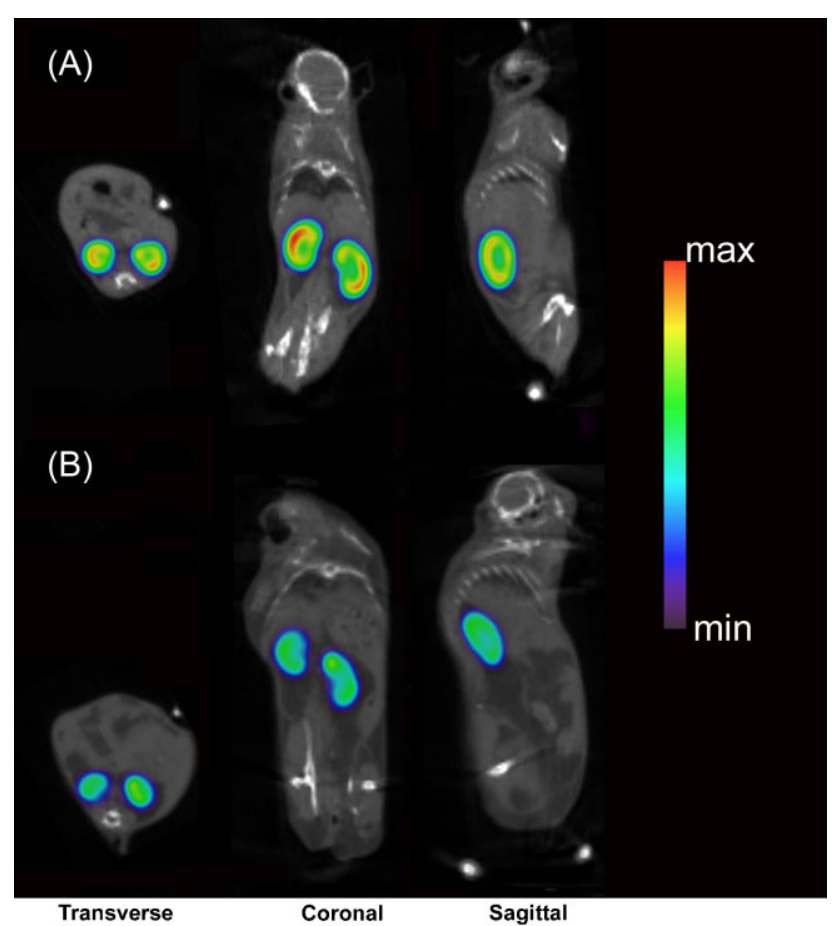

Figure 3. Pinhole SPECT/microCT images of megalin-wildtype $(A)$ and megalin-knockout mice (B) at $1 \mathrm{~h}$ p.i. of ${ }^{99 \mathrm{~m}} \mathrm{Tc}-7 \mathrm{C} 12$. NIH color scale is used and images are equally scaled to correct for injected activity.

combination with lysine and gelofusine (LysCoad + GeloCoad) at $1.5 \mathrm{~h}$ p.i. is summarized in Table 2 . The ex vivo data confirmed the image data described above. LysCoad + GeloCoad significantly reduced renal uptake of ${ }^{99 \mathrm{~m}} \mathrm{Tc}-7 \mathrm{C} 12$ by $42.83 \pm 3.15 \%$ compared with control. As shown by image analysis, there was no significant difference in the accumulation of the tracer in the liver, spleen and muscle $(p>0.05)$; however tumor uptake of the tracer was significantly higher in LysCoad + GeloCoad treated mice which also reflected the tumor-to-background ratios. The tumorto-muscle ratio for LysCoad + GeloCoad and control group was $32.81 \pm 1.76$ vs $26.74 \pm 4.61$ ( $p>0.05)$; the tumor-to-blood ratio was $7.83 \pm 1.65$ vs $5.69 \pm 0.98(p>0.05)$ respectively.

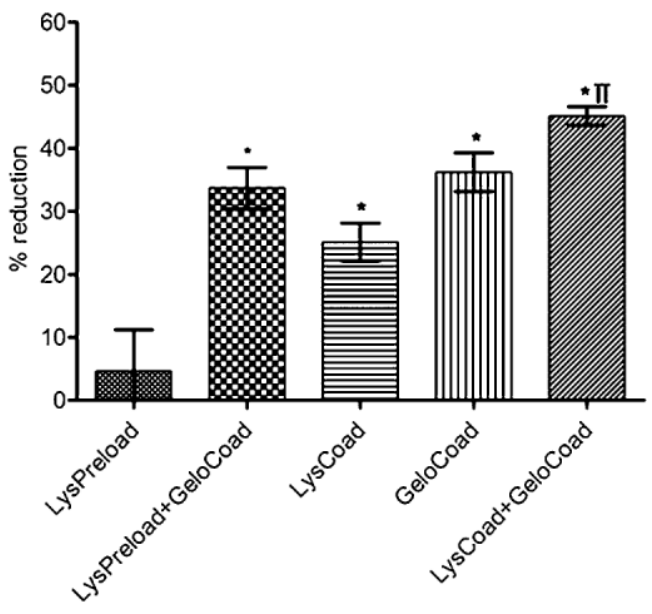

Figure 4. Reduction of renal retention of ${ }^{99 \mathrm{~m}} \mathrm{Tc}-7 \mathrm{C} 12$ in $\mathrm{CD}-1$ mice. Mice received pre- or co-administration of lysine alone or in combination with gelofusine and were euthanized at $1.5 \mathrm{~h}$ p.i. of ${ }^{99 \mathrm{~m}} \mathrm{Tc}-7 \mathrm{C} 12$. The total activity in the kidneys was quantified and the percentage of reduction was calculated. * Statistically significant compared to lysine preload $p<0.05, \Pi p<0.05$ compared to lysine coadministration. Data are shown as mean \pm SEM. Lysine preload at $30 \mathrm{~min}$ before tracer injection (LysPreload), (lysine preload at $30 \mathrm{~min}$ before tracer injection+gelofusine coadministration with the tracer (LysPreload+GeloCoad), lysine coadministration with the tracer (LysCoad), gelofusine coadministration with the tracer (GeloCoad) and lysine plus gelofusine coadministration with the tracer (LysCoad+GeloCoad).

The blood clearance curves were biphasic, showing fast and similar elimination in both groups (Fig. 6). The calculated $\alpha$ and $\beta$-half-lives were 0.19 and $4.68 \mathrm{~min}$ for control, respectively, and 0.18 and $3.89 \mathrm{~min}$ for LysCoad + GeloCoad treated mice, respectively.

\section{DISCUSSION}

In the development of new tracers it is important to show high affinity and specific binding of the tracer to the molecular target both in vitro and in vivo. It is equally important for a tracer to

Table 1. Biodistribution of ${ }^{99 \mathrm{~m}} \mathrm{Tc}-7 \mathrm{C} 12$ in megalin-knockout and megalin-wild-type mice euthanized at $1.5 \mathrm{~h}$ p.i.

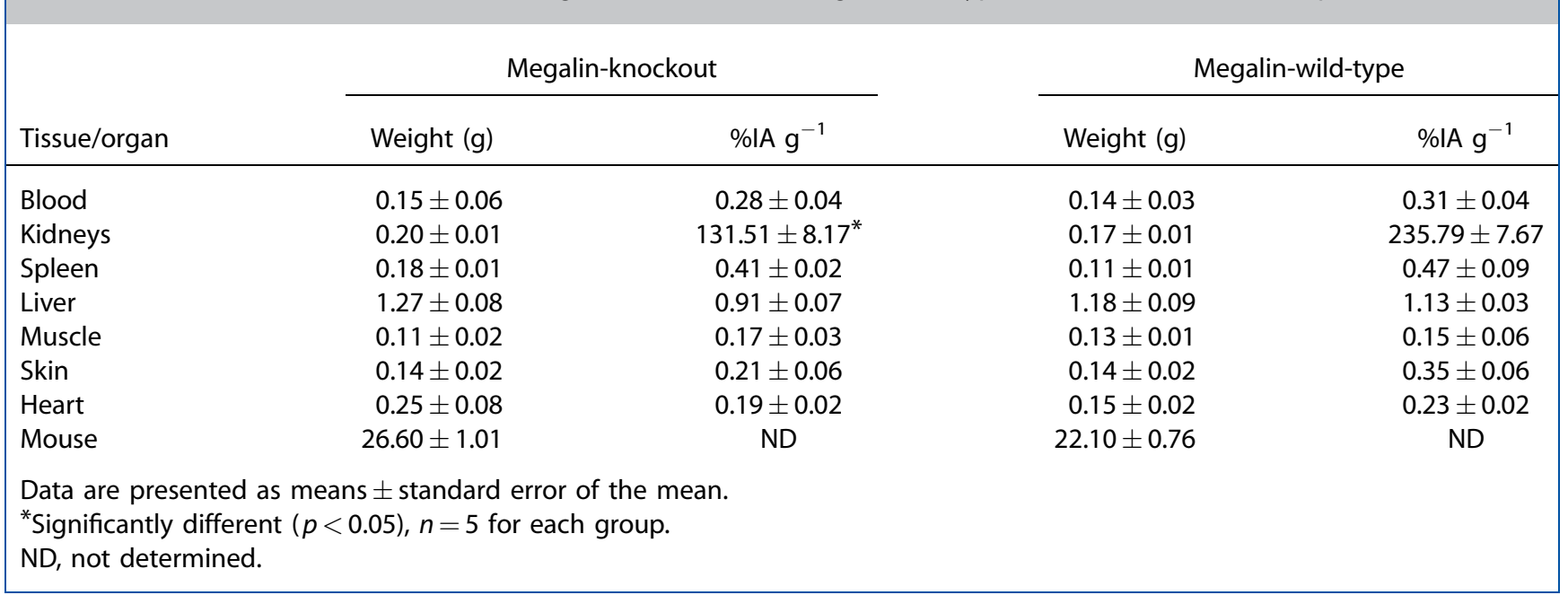




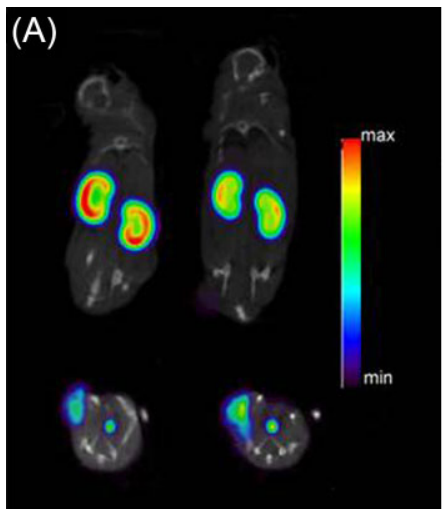

(B)

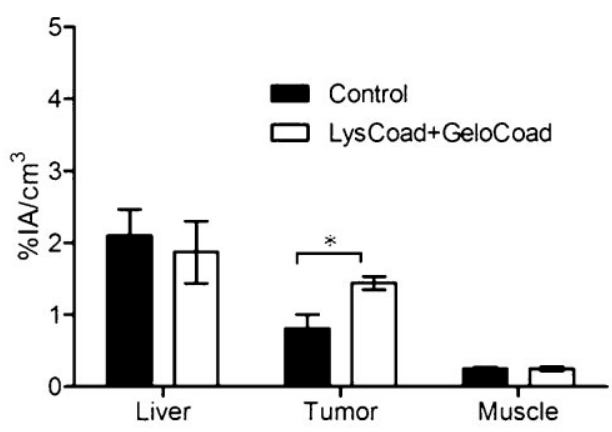

Figure 5. (A) Pinhole SPECT/microCT images of mice bearing A431 xenografts acquired at $1 \mathrm{~h}$ p.i. showing less tracer uptake in the kidneys (top panel) and higher activity in the tumor of LysCoad+GeloCoad treated mice (bottom panel). NIH color scale is used and images are equally scaled to correct for the injected activity. (B) Image quantification depicting significantly higher uptake in the tumor of LysCoad+GeloCoad treated mice. Data shown are mean \pm SEM. * Significant $p<0.05$.

exhibit favorable biodistribution and pharmacokinetics for it to be translated into a clinical application. The ideal tracer only accumulates at the target and is rapidly cleared from non-target tissues. Clearance can be hepatic and/or renal. Hepatic and subsequent intestinal elimination is to be avoided for cancer targeting probes because it obscures liver metastasis and intra-abdominal lesions. Kidney clearance with urinary elimination is preferable. This requires relatively hydrophilic molecules with a molecular size that is inferior to $60 \mathrm{kDa}$ threshold for glomerular filtration. Nanobodies fit this description: they are hydrophilic, have a molecular size of $15 \mathrm{kDa}$, have a fast blood clearance and show low liver uptake (10). Together with their characteristic of specific targeting with affinities in the nanomolar range, they represent an interesting class of probes for the generic development of molecular imaging agents. The main disadvantage at present is the relatively high kidney retention. This problem is common to most small proteins or peptide tracers. The kidney retrieves useful substances from the glomerular filtrate and radiometal-chelated amino acids are trapped, leading to high absorbed doses of radiation (12). Since the radiation dose to the kidney might be a dose-limiting factor in

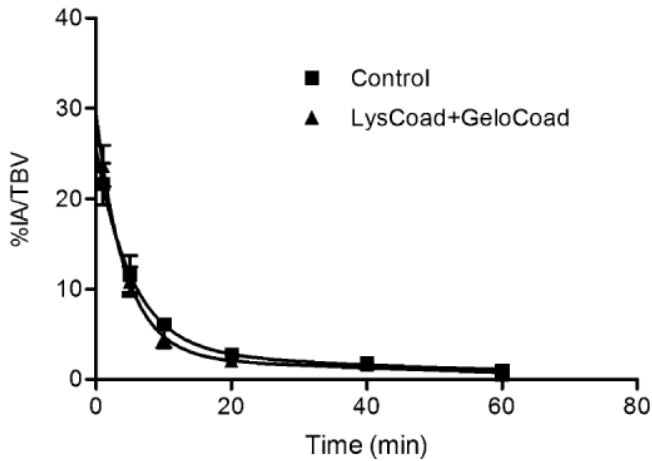

Figure 6. Blood clearance of ${ }^{99 \mathrm{~m}} \mathrm{Tc}-7 \mathrm{C} 12$ in Control $(\mathrm{n}=6)$ and LysCoad+GeloCoad $(n=6)$ in mice with a xenograft bearing A431 tumour. Blood samples were collected at indicated time points, their activity was determined with a gamma-counter and expressed as percentage of the administered activity per total blood volume (\%IA/TBV). Biologigal halflife in plasma was determined using a two phase biexponential decay of nonlinear regression fit (GraphPad Prism).

Table 2. Biodistribution of ${ }^{99 \mathrm{~m}} \mathrm{Tc}-7 \mathrm{C} 12$ injected either alone (control) or in combination with lysine and gelofusine (LysCoad + GeloCoad) in mice bearing a tumor xenograft euthanized at $1.5 \mathrm{~h}$ p.i.

LysCoad + GeloCoad

\begin{tabular}{lr} 
Tissue/organ & Weight $(\mathrm{g})$ \\
\hline Blood & $0.34 \pm 0.07$ \\
Kidneys & $0.26 \pm 0.01$ \\
Spleen & $0.16 \pm 0.01$ \\
Liver & $1.48 \pm 0.05$ \\
Muscle & $0.13 \pm 0.01$ \\
Tumor & $0.61 \pm 0.13$ \\
Mouse & $28.08 \pm 0.96$
\end{tabular}

$\% \mathrm{IA} \mathrm{g}^{-1}$

$0.70 \pm 0.05$

$68.95 \pm 3.76^{*}$

$0.94 \pm 0.39$

$2.55 \pm 0.66$

$0.16 \pm 0.02$

$4.70 \pm 0.43^{*}$

ND
Control

\begin{tabular}{rc} 
Weight $(\mathrm{g})$ & $\mathrm{\% lA} \mathrm{g}^{-1}$ \\
\hline $0.42 \pm 0.05$ & $0.68 \pm 0.08$ \\
$0.26 \pm 0.01$ & $120.61 \pm 6.91$ \\
$0.12 \pm 0.01$ & $1.19 \pm 0.29$ \\
$1.41 \pm 0.10$ & $3.50 \pm 0.77$ \\
$0.14 \pm 0.02$ & $0.15 \pm 0.02$ \\
$0.46 \pm 0.06$ & $3.54 \pm 0.25$ \\
$28.08 \pm 1.53$ & $\mathrm{ND}$
\end{tabular}

Data are presented as mean \pm standard error of the mean.

*Significantly different $(p<0.05), n=6$ for each group.

ND, not determined. 
nanobody imaging and therapy, optimization of the tumor radiation dose while avoiding too much radiation damage to the kidneys is very necessary and will enlarge therapeutic window. The kidney retention of radiopharmaceuticals is not only dependent on the characteristics of the targeting molecule itself, but is also dependent on the type of chelator or radionuclides and on the stability of the radiolabeled compound $(25,26)$. We used nanobody-labeled site specifically with technetium tricarbonyl $\left.\left({ }^{99 \mathrm{~m}} \mathrm{Tc}(\mathrm{CO})_{3}\left(\mathrm{H}_{2} \mathrm{O}\right)_{3}\right]^{+}\right)$via its hexahistidine tag inserted genetically for immobilized metal ion affinity chromatography purification purpose. $\left[{ }^{99 \mathrm{~m}} \mathrm{Tc}(\mathrm{CO})_{3}\left(\mathrm{H}_{2} \mathrm{O}\right)_{3}\right]^{+}$easily changes its three water molecules for a wide variety of donor ligands including histidine to form a stable complex. Here we have shown that ${ }^{99 \mathrm{~m}} \mathrm{Tc} 7 \mathrm{C} 12$ is extremely stable in vitro in human serum while in kidneys the radiotracer is metabolized to some extent. Nanobody retention is mainly localized in the kidney cortex. Using a megalin-knockout mouse model we could prove that this mechanism is responsible for at least $40 \%$ of the total retention in the kidneys. We also showed that it is feasible to reduce kidney retention without negatively affecting targeted tumor uptake using gelofusine and lysine administration. Renal reabsorption of proteins is predominantly mediated by megalin and cubilin receptors. Both are endocytic receptors that are expressed on the apical side of proximal tubule cells. They are co-localized in the clathrin-coated pits of the brush border and undergo endocytosis with trafficking towards the lysosomes (27). In the lysosomes, proteins are degraded into amino acids that are subsequently released at the basolateral side into the peritubular capillaries. Megalin can bind and internalize ligands, whereas cubilin requires the presence of megalin for internalization. Both receptors interact with a wide variety of ligands and accept multiple ligands simultaneously $(28,29)$. The affinity of the interaction is variable but the efficiency of the process is related to the high expression levels, allowing for high capacity reabsorption. Some proteins bind both receptors; others are specific for one receptor $(28,29)$. From our study in megalin-knockout mice we can clearly show that megalin is at least partially related to the renal retention of ${ }^{99 \mathrm{~m}} \mathrm{Tc}-7 \mathrm{C} 12$ nanobody. The relation might even be stronger than the $44 \%$ that we showed because the knockout is not complete and a low level of megalin is still present in these animals (30). The total renal retention also varies between different animal strains. Megalin-wild-type had almost two-fold higher renal retention compared with athymic nude mice. Therefore the $40 \%$ involvement of megalin might not be predictive for all animal strains and species or even human. Since cubilin requires megalin for internalization we also cannot distinguish what receptor ${ }^{99 m}$ Tc-7C12 actually binds. However it does open the possibility of interfering with this mechanism in order to reduce kidney retention. Infusion of positively charged amino acids, succinylated gelatin (gelofusine) or albumin fragments that competitively interact with the megalin/cubilin mediated recognition of radiolabeled peptides or antibody fragments can reduce renal retention (31-33). Some of these approaches are clinically validated and have become part of the standard protocols in peptide receptor radionuclide therapy $(33,34)$. However, this principle is not applicable to all compounds and efficiency can vary greatly between different types of radiolabeled compounds (35). Here we show that this principle does apply for ${ }^{99 \mathrm{~m}} \mathrm{Tc}-7 \mathrm{C} 12$ nanobody. Coadministration of lysine and/or gelofusine at the time of tracer administration effectively reduces the kidney retention by approximately $40 \%$. The combination of gelofusine and lysine showed the strongest reduction, although we could not show strong statistical significance compared with gelofusine alone. The infusion of these compounds did not increase the retention of the tracer in the body but effectively directed the renal filtered nanobodies towards elimination via the urinary bladder. This was calculated using total body microSPECT imaging that allows an exact measurement of the residual total body activity. Here we measured an extra $20 \%$ urinary elimination of the injected activity at $1 \mathrm{~h}$ post-injection that is related to the gelofusine plus lysine coadministration. Higher tumor uptake was observed in animals that received gelofusine plus lysine coadministration. It is known that gelofusine increases cardiac output and thereby might also increase the blood flow (36) and the delivery of nanobody to the tumor. As a result tumor-to-background ratios were also better after gelofusine and lysine administration.

Other mechanisms are probably also involved in the reabsorption. These include a variety of organic ion transporters (37) and fluid phase endocytosis (pinocytosis), which is not receptor mediated. For the latter mechanism it is not possible to interfere specifically but increasing urine production through hydration of the subject might reduce this pathway. Such hydration is always beneficial for reducing the residence time of most radiolabeled probes in the kidneys and urinary system.

An alternative approach for reducing radionuclide trapping in the kidney is the use of different chelator and radioisotopes or the introduction of a specific spacer sequence between the targeting probe and the radionuclide. Such a spacer can be designed so that it is enzymatically cleaved in the kidney, thereby releasing the radionuclide from the protein $(38,39)$. The introduction of a spacer sequence is compatible with the nanobody format and an interesting option for future research.

In summary, ${ }^{99 \mathrm{~m}}$ Tc-labeled $7 \mathrm{C} 12$ nanobody is intensively accumulated in the renal cortex. The endocytotic receptor megalin is involved in this accumulation, which can be partially inhibited by coinfusion of gelofusine and/or lysine with the tracer. Although this methodology allows for optimization of imaging protocol using nanobodies, further improvements are needed before using these molecules for radionuclide therapy.

\section{Acknowledgements}

The research at ICMI is funded by the Interuniversity Attraction Poles Programme, Belgian State, Belgian Science Policy. Lea Olive Tchouate Gainkam is a Ph.D. fellow of the Horizontal Research Axis (HOA) grant of the Vrije Universiteit Brussel. Tony Lahoutte is a Senior Clinical Investigator of the Research Foundation, Flanders (FWO). The authors acknowledge Ms Cindy Peleman for her technical assistance with the small animal pinhole SPECT/ microCT imaging. The authors are grateful to Lieven Huang for producing the nanobody.

\section{References}

1. Holliger P, Hudson PJ. Engineered antibody fragments and the rise of single domains. Nat Biotechnol 2005; 23: 1126-1136.

2. Adams GP, Tai MS, McCartney JE, et al. Avidity-mediated enhancement of in vivo tumor targeting by single-chain Fv dimers. Clin Cancer Res 2006; 12: 1599-1605.

3. Todorovska A, Roovers RC, Dolezal O, et al. Design and application of diabodies, triabodies and tetrabodies for cancer targeting. J Immunol Meth 2001; 248: 47-66.

4. Sundaresan G, Yazaki PJ, Shively JE, et al. 124l-labeled engineered anti-CEA minibodies and diabodies allow high-contrast, antigen- 
specific small-animal PET imaging of xenografts in athymic mice. J Nucl Med 2003; 44: 1962-1969.

5. Tang Y, Wang J, Scollard DA, et al. Imaging of HER2/neu-positive BT-474 human breast cancer xenografts in athymic mice using (111)In-trastuzumab (Herceptin) Fab fragments. Nucl Med Biol 2005; 32: 51-58.

6. Burvenich IJ, Schoonooghe $\mathrm{S}$, Blanckaert $\mathrm{P}$, et al. Biodistribution and planar gamma camera imaging of (123)I- and (131)I-labeled $F\left(a b^{\prime}\right)(2)$ and Fab fragments of monoclonal antibody $14 C 5$ in nude mice bearing an A549 lung tumor. Nucl Med Biol 2007; 34: 257-265.

7. Lauwereys M, Arbabi Ghahroudi M, Desmyter A, et al. Potent enzyme inhibitors derived from dromedary heavy-chain antibodies. EMBO J 1998; 17: 3512-3520.

8. Vincke C, Loris R, Saerens D, et al. General strategy to humanize a camelid singledomain antibody and identification of a universal humanized nanobody scaffold. J Biol Chem 2009; 284: 3273-3284.

9. Saerens $D$, Pellis $M$, Loris $R$, et al. Identification of a universal VHH framework to graft non-canonical antigen-binding loops of camel single-domain antibodies. J Mol Biol 2005; 352: 597-607.

10. Gainkam LO, Huang L, Caveliers V, et al. Comparison of the biodistribution and tumor targeting of two $99 \mathrm{mTc}$-labeled antiEGFR nanobodies in mice, using pinhole SPECT/micro-CT. J Nucl Med 2008; 49: 788-795.

11. Huang L, Gainkam LO, Caveliers V, et al. SPECT imaging with 99mTc-labeled EGFR-specific nanobody for in vivo monitoring of EGFR expression. Mol Imag Biol 2008; 10: 167-175.

12. Behr TM, Goldenberg DM, Becker W. Reducing the renal uptake of radiolabeled antibody fragments and peptides for diagnosis and therapy: present status, future prospects and limitations. Eur J Nucl Med 1998; 25: 201-212.

13. Behr TM, Sharkey RM, Juweid ME, et al. Reduction of the renal uptake of radiolabeled monoclonal antibody fragments by cationic amino acids and their derivatives. Cancer Res 1995: 55: 3825-3834.

14. Miao Y, Fisher DR, Quinn TP. Reducing renal uptake of 90Y- and 177Lu-labeled alpha-melanocyte stimulating hormone peptide analogues. Nucl Med Biol 2006; 33: 723-733.

15. Akizawa $\mathrm{H}$, Arano $\mathrm{Y}$, Mifune $\mathrm{M}$, et al. Effect of molecular charges on renal uptake of 111 In-DTPA-conjugated peptides. Nucl Med Biol 2001; 28: 761-768.

16. van Eerd JE, Vegt E, Wetzels JF, et al. Gelatin-based plasma expander effectively reduces renal uptake of $111 \mathrm{ln}$-octreotide in mice and rats. J Nucl Med 2006; 47: 528-533.

17. Vegt E, Wetzels JF, Russel FG, et al. Renal uptake of radiolabeled octreotide in human subjects is efficiently inhibited by succinylated gelatin. J Nucl Med 2006; 47: 432-436.

18. Rolleman EJ, Bernard BF, Breeman WA, et al. Molecular imaging of reduced renal uptake of radiolabelled [DOTA0,Tyr3] octreotate by the combination of lysine and Gelofusine in rats. Nuklearmedizin 2008; 47: 110-115.

19. Roovers RC, Laeremans $T$, Huang $L$, et al. Efficient inhibition of EGFR signaling and of tumour growth by antagonistic antiEFGR Nanobodies. Cancer Immunol Immunother 2007; 56: 303-317.

20. Velikyan I, Sundberg $A L$, Lindhe $O$, et al. Preparation and evaluation of (68)Ga-DOTA-hEGF for visualization of EGFR expression in malignant tumors. J Nucl Med 2005; 46: 1881-1888.
21. Leheste JR, Rolinski B, Vorum H, et al. Megalin knockout mice as an animal model oflow molecular weight proteinuria. Am J Pathol 1999; 155: 1361-1370.

22. Leheste JR, Melsen F, Wellner M, et al. Hypocalcemia and osteopathy in mice with kidney-specific megalin gene defect. FASEB J 2003; 17: 247-249.

23. Vanhove C, Defrise M, Lahoutte T, Bossuyt A. Three-pinhole collimator to improve axial spatial resolution and sensitivity in pinhole SPECT. Eur J Nucl Med Mol Imag 2008; 35: 407-415.

24. Loening AM, Gambhir SS. AMIDE: a free software tool for multimodality medical image analysis. Mol Imag 2003; 2: 131-137.

25. Orlova A, Nilsson FY, Wikman $M$, et al. Comparative in vivo evaluation of technetium and iodine labels on an anti-HER2 affibody for single-photon imaging of HER2 expression in tumors. J Nucl Med 2006; 47: 512-519.

26. Ekblad T, Orlova A, Feldwisch $J$, et al. Positioning of 99mTc-chelators influences radiolabeling, stability and biodistribution of Affibody molecules. Bioorg Med Chem Lett 2009; 19: 3912-3914.

27. Birn $\mathrm{H}$, Fyfe JC, Jacobsen $\mathrm{C}$, et al. Cubilin is an albumin binding protein important for renal tubular albumin reabsorption. J Clin Invest 2000; 105: 1353-1361.

28. Verroust PJ, Christensen El. Megalin and cubilin - the story of two multipurpose receptors unfolds. Nephrol Dial Transplant 2002; 17: 1867-1871.

29. Christensen El, Birn H. Megalin and cubilin: multifunctional endocytic receptors. Nat Rev Mol Cell Biol 2002; 3: 256-266.

30. de Jong $M$, Barone $R$, Krenning $E$, et al. Megalin is essential for renal proximal tubule reabsorption of (111)In-DTPA-octreotide. J Nucl Med 2005; 46: 1696-1700.

31. Vegt $E$, Eek A, Oyen WJ, et al. Albumin-derived peptides efficiently reduce renal uptake of radiolabelled peptides. Eur J Nucl Med Mol Imag 2010; 37(2): 226-234.

32. Vegt $E$, van Eerd JE, Eek $A$, et al. Reducing renal uptake of radiolabeled peptides using albumin fragments. J Nucl Med 2008; 49: 1506-1511.

33. Behr TM, Becker WS, Sharkey RM, et al. Reduction of renal uptake of monoclonal antibody fragments by amino acid infusion. J Nucl Med 1996; 37: 829-833.

34. Rolleman EJ, Valkema R, de Jong M, Kooij PP, Krenning EP. Safe and effective inhibition of renal uptake of radiolabelled octreotide by a combination of lysine and arginine. Eur J Nucl Med Mol Imag 2003; 30: 9-15.

35. Gotthardt M, van Eerd-Vismale J, Oyen WJ, et al. Indication for different mechanisms of kidney uptake of radiolabeled peptides. J Nucl Med 2007; 48: 596-601.

36. Wan L, Bellomo R, May CN. A comparison of $4 \%$ succinylated gelatin solution versus normal saline in stable normovolaemic sheep: global haemodynamic, regional blood flow and oxygen delivery effects. Anaesth Intensive Care 2007; 35: 924-931.

37. Stahl AR, Wagner B, Poethko T, et al. Renal accumulation of [111 In]DOTATOC in rats: influence of inhibitors of the organic ion transport and diuretics. Eur J Nucl Med Mol Imag 2007; 34: 2129-2134.

38. Arano $Y$, Fujioka $Y$, Akizawa $H$, et al. Chemical design of radiolabeled antibody fragments for low renal radioactivity levels. Cancer Res 1999; 59: 128-134.

39. Fujioka $Y$, Arano $Y$, Ono $M$, et al. Renal metabolism of 3'-iodohippuryl N(epsilon)-maleoyl-L-lysine (HML)-conjugated Fab fragments. Bioconjug Chem 2001; 12: 178-185. 